ten times as readily. These values imply that the molecular weight is determined by the ratio of propagation to transfer, remaining almost constant up to very high rates of polymerization. Thus the rate a $25^{\circ}$ giving a mean molecular weight only 33 per cent less than that of the 'transfer polymer' is sixty times the corresponding rate for styrene. Our value for the velocity constant of propagation is very much less than that which may be deduced from Melville's $\mathrm{s}^{2}$ experiments on the sensitized polymerization of methyl methacrylate in the gas phase $\left(\sim 3 \times 10^{6}\right.$ at $\left.20^{\circ}\right)$. This corresponds to a frequency factor of $3 \times 10^{10}$, assuming that the energy of activation for propagation is 5-6 cal. (and it is not likely to be less). Since the propagation reaction is certainly sterically hindered, this value must be too high. In any event, it is not consistent with Burnett and Melville's ${ }^{3}$ results for vinyl acetate (in which there is less hindrance), which lead to a frequency factor of $1.35 \times 10^{6}$

In the photopolymerization of liquid methacrylate a rapid polymerization is observed after the light has been cut off. This is independent of the normal photochemical after-effect. A similar result is obtained when the vapour is subjected to a silent electrical discharge for a few minutes. None of these features can be attributed to surface effects. All our results can be explained if a catalyst is formed by the action of light or the electric discharge.

Melville ${ }^{2}$ has previously observed a somewhat similar phenomenon in the photopolymerization of methacrylate vapour, and has concluded in the photopolymerization of methacrylate vapour, and has concluded that the growing chains are of special type which do not terminate,
and which are not radicals but contain activated double bonds. We and which are not radicals but contain activated double bonds. We do not find this concept necessary in our case, as the chains appear to results can also be explained by the formation of catalyst, or remova of inhibitor, by light, together with absorption of monomer by the film of polymer. This interpretation seems preferable to us, as Melville's activated double bonds do not appear to conform to current physical ideas.

A full account of these experiments will be published elsewhere in due course.

Courtaulds, Ltd.,

M. J. S. DEWAR

Courtaulds, Ltd.,
Islet, Maidenhead Court,

Maidenhead, Berks. Aug. 12.

Bamford, C. H., and Dewar, M. J. S., Nature, 15\%, 845 (1946). 2 Melville, H. W., Proe. Roy. Soc., A, 163, 511 (1937)

${ }^{3}$ Burnett, G. M., and Melville, H.' W., Nature, 158, 661 (1945).

\section{Hydrolysis of Chloral in Heavy Hydrogen Water}

IN the presence of an alkali, chloral undergoes a fission at the $\mathrm{C}-\mathrm{C}$ bond with the formation of chloroform and an alkali formate. Thi communication gives a preliminary report on the investigation of this reaction in the presence of heavy hydrogen water. 1 c.c. of a solution containing 0.002 mole of chloral hydrate is mixed with 1 c.c. of a solution containing 0.002 mole of sodium hydroxide. The reaction is complete within one minute at $30^{\circ} \mathrm{C}$. and, after this period, the reaction mixture is frozen. 'The chloroform and the water are removed by pumping off the vapours of these substances from the frozen mixture. When the sodium formate which remains in the vessel is perfectly dry, it is decomposed by the action of heat in the vessel is and hydrogen are formed and the latter is then converted to water. The excess density of this water is determined by the micro-pyknometer method of Gilfillan and Polanyi ${ }^{1}$. The results of experiments in the presence of normal water and of heavy hydrogen water respectively, are listed below. The excess density of the original heavy water, allowing for the exchange between the hydrogen of the hydroxyl groups of the reagents and that of the water was 2650 p.p.m.

$\begin{array}{cc}\text { Excess density in p.p.m. } \\ \text { Normal water } & \text { Heavy water } \\ 0 & 41 \\ 0 & 785 \\ 0 & 124 \\ 0 & 280\end{array}$

The results of experiments in the presence of heavy hydrogen water are rather variable; but as the average excess density is only about 10 per cent of the excess density of the original heavy water, the hydrogen in the formate ion is most probably the same as that in the aldehyde group of the original chloral molecule. The mechanism presumably involves an attack on the carbon of the aldehyde group by the hydroxyl ion, followed by a fission of the $\mathrm{C}-\mathrm{C}$ bond and formaby the hydroxyl ion,
tion of a $\mathrm{CCl}_{3}^{-}$ion.<smiles></smiles>

The process is then completed by the neutralization of the formic acid and reaction between the $\mathrm{CCl}_{3}{ }^{-}$ion and water.

$$
\begin{array}{ll}
\mathrm{OD}^{-}+\mathrm{H}-\mathrm{COOD} & \longrightarrow \mathrm{DOD}+\mathrm{H}-\mathrm{COO}^{-} \\
\mathrm{CCl}_{3}^{-}+\mathrm{DOD} & \longrightarrow \mathrm{DCCl}_{3}+\mathrm{OD}^{-}
\end{array}
$$

The observed excess density in the case of experiments carried out in the presence of heavy hydrogen water cannot be attributed to the exchange of hydrogen between the formate ion and water as this is a very slow process ${ }^{2}$. The hydrolysis of the heavy hydrogen chloroform would lead to the formation of a formate ion containing heavy hydrogen,

$\mathrm{DCCl}_{3}+4 \mathrm{NaOH} \longrightarrow \mathrm{D}-\mathrm{COONa}+3 \mathrm{NaCl}$;

but titration of the final reaction mixture with a standard silver nitrate solution shows that, under the experimental conditions, this reaction does not occur to any appreciable extent. It appears that the interchange of hydrogen between the water and the hydrogen of the aldehyde group in the chloral molecule is the most likely explanation of the results.

The corresponding exchange in the case of acetaldehyde is slow ${ }^{3}$ but in the chloral molecule the $\mathrm{CCl}^{-}$group may have an activating effect on the hydrogen of the aldehyde group. The variable results which have been obtained are believed to indicate that the exchange occurs at a fairly rapid rate under alkaline conditions. "This latter point is being investigated.

I. IAAUDER
S. E. WRIGHT

Department of Chemistry,

University of Queensland,

Brisbane.

Aug. 6.

${ }^{1}$ Gilfillan, E. S., and Polanyi, M., Z. phys. Chem., A, 166, 255 (1933) 2 Small, P. A., and Wolfenden, J. H., J. Chem. Soc., 1811 (1936). $441(1938)$

\section{Central Institute of Management}

Writh reference to a report of the committee appointed by the President of the Boird of Trade under the chairmanship of Sir Clive Baillieu entitled "A Central Institute of Management", it appear that the content of management under the proposed Institute of Management will cover the "common, broad functions of management" and will embody both "research" and "training and education". It ment or administration, such for example as the principle of delegation of authority, since they are current throughout all administrative or managerial fields.

With regard to the various fields of management or administration these are to be the provinces of the ad hoc bodies concerned, where such exist, and may be divided into two main classes: public management exist, and may be divided into two main classes : public management included central and local government administration, which involves, inter alia, the administration of the defence forces, social administration, inter alia, the administration of the defence forces, social administration and the management of the public utilities. Within the scope of
non-public management lie such special fields as industrial administration, commercial or business administration, the administration of agriculture and institutional administration. Within the latter clas may be grouped such functions as ecclesiastical administration and the administration of learned bodies both scientifle and otherwise.

Among the activities of the Central Institute of Management are to be the "developing of organization in spheres of management not already covered" and the "developing of new organizations wherever necessary". The conjoint study of the management or administration of technical learned bodies, such as scientific and technical societies, institutes and associations on one hand, and of research associations institutes and associations on one hand, and of research associations
on the other, has long been neglected. In view of the ever-increasing importance of science, in the development and dissemination of which the scientific and technieal learned bodies play an essential and unique part, I suggest that the Institute of Management might consider the setting up of an affiliated body for this purpose in the form of an institute or association of professional administrators of such scientific and technical bodies.

3, Little Lane,

P. A. WELTS

Bradford, Yorkshire.

1 Nature, 15\%, 601 (1946).

\section{Charles Mason and Jeremiah Dixon}

DURING recent years, I have published articles ${ }^{1}$ on Charles Mason and Jeremiah Dixon, attempting to present their survey of the Maryland-Pennsylvania boundary (1763-1768), as a chapter of contemporary science and technology in Great Britain. The work is being continued and extended, and the American Philosophica Society has made a grant of funds to secure copies of source materia dealing with the careers of the two men.

I have established correspondence with a number of scholars in Great Britain and now wish to extend my contacts to others who may know of records of the two astronomer-surveyors and of the equipment they used.

Information is needed about the early training of the two. Where were they from the spring of 1762 to midsummer of 1763 ? Where did Mason live while working for the Nautical Almanac during the 1770's? Why did Mason leave England and migrate to Philadelphia during the 1780 's ? What did Dixon do during the $1770^{\prime} \mathrm{s}$, the last years of his life? And where are records of their personal lives, their scientific and technological work, and of their instruments to be found other than in publications of the Royal Society and in the Nautical Almanac?

Suggestions will be duly acknowledged and credited.

Randal Morgan Laboratory of Physics,

THOMAS D. COPE University of Philadelphia.

"Pennsylvania History", 6, 205-220; 11, 155; 12, 24. Proc. Pennsylvania Acad. Ści., 18, 72; '19, 79. Ścientific Monthly, 62, 541 . 